\title{
OPEN Non-specific interactions of antibody-oligonucleotide conjugates with living cells
}

\author{
Victor Lehot ${ }^{1}$, Isabelle Kuhn ${ }^{1}$, Marc Nothisen ${ }^{1}$, Stéphane Erb², Sergii Kolodych ${ }^{3}$, \\ Sarah Cianférani ${ }^{2}$, Guilhem Chaubet ${ }^{1}$ \& Alain Wagner ${ }^{1 凶}$
}

Antibody-Oligonucleotide Conjugates (AOCs) represent an emerging class of functionalized antibodies that have already been used in a wide variety of applications. While the impact of dye and drug conjugation on antibodies' ability to bind their target has been extensively studied, little is known about the effect caused by the conjugation of hydrophilic and charged payloads such as oligonucleotides on the functions of an antibody. Previous observations of non-specific interactions of nucleic acids with untargeted cells prompted us to further investigate their impact on AOC binding abilities and cell selectivity. We synthesized a series of single- and double-stranded AOCs, as well as a human serum albumin-oligonucleotide conjugate, and studied their interactions with both targeted and non-targeted living cells using a time-resolved analysis of ligand binding assay. Our results indicate that conjugation of single strand oligonucleotides to proteins induce consistent non-specific interactions with cell surfaces while double strand oligonucleotides have little or no effect, depending on the preparation method.

Antibody-oligonucleotide conjugates (AOCs) have received increasing attention as an emerging class of chimeric biomolecules. Combining the specific binding ability of antibodies with the vast structural and functional properties of oligonucleotides (ONs), these conjugates have found a wide variety of applications as imaging, detection and therapeutic agents ${ }^{1}$.

All of these functions primarily require the discrimination of the targeted cell type via specific binding of the AOC to its protein target. Reaching high efficacy in therapeutic applications thus requires, among other, both a high affinity for the targeted protein at the targeted cell surface and low interactions with the other, nontargeted, cells.

In a recent work ${ }^{2}$, we investigated the ability of AOC constructs (termed DNA-linked ADCs) to carry and deliver a small-molecule drug into a targeted cell in a selective fashion. To our surprise, we observed that while our DNA-linked ADC (based on the anti-HER2 monoclonal antibody trastuzumab) showed a similar toxicity profile on HER2 ${ }^{+}$cells to classical covalent conjugates, it also showed low but unexpected toxicity on the control HER2 ${ }^{-}$cell line. We hypothesized that this toxicity was the result of a non-specific interaction of the conjugate with HER2 ${ }^{-}$cells induced by the ON linker. This puzzling observation motivated us to further investigate the impact of ON conjugation on the cell binding properties of antibodies and proteins.

ONs, because of their hydrophilic nature and multiple negative charges, constitute a singular type of payload for which a few literature reports have highlighted non-specific interactions with cell membranes. In 1995, Walker et al. ${ }^{3}$ described the synthesis and in vitro cellular uptake of an anti-transferrin receptor antibody-antisense ON conjugate (the antisense ON being a single-stranded DNA) and observed non-specific cell association for both control IgG-ssON conjugate and free ON. The "non-specific" interactions of non-modified ${ }^{4}$ and dye-labelled ${ }^{5}$ ONs with cell membranes have also been reported. However, despite these early warnings, the effect of ON conjugation on antibody selectivity remains understudied.

To shed light on such potentially determinant effect, we compared the interactions of various protein-ON conjugates, unconjugated proteins and free ONs with live cells using a time-resolved analysis of ligand binding assay. This technique allows the study of interactions in real-time on non-treated, live cells in culture medium, and in the presence of serum, a situation resembling in vivo conditions. Importantly, it requires no washing step that could wash off compounds before their detection ${ }^{6}$, revealing weak interactions with fast dissociation rates.

${ }^{1}$ Bio-Functional Chemistry (UMR 7199), LabEx Medalis, University of Strasbourg, 74 Route du Rhin, 67400 Illkirch-Graffenstaden, France. ${ }^{2}$ BioOrganicMass Spectrometry Laboratory (LSMBO), IPHC, University of Strasbourg, 25 rue Becquerel, 67087 Strasbourg, France. ${ }^{3}$ Syndivia SAS, ISIS, 8 allée Gaspard Monge, 67000 Strasbourg, France. ${ }^{\varpi}$ email: alwag@unistra.fr 


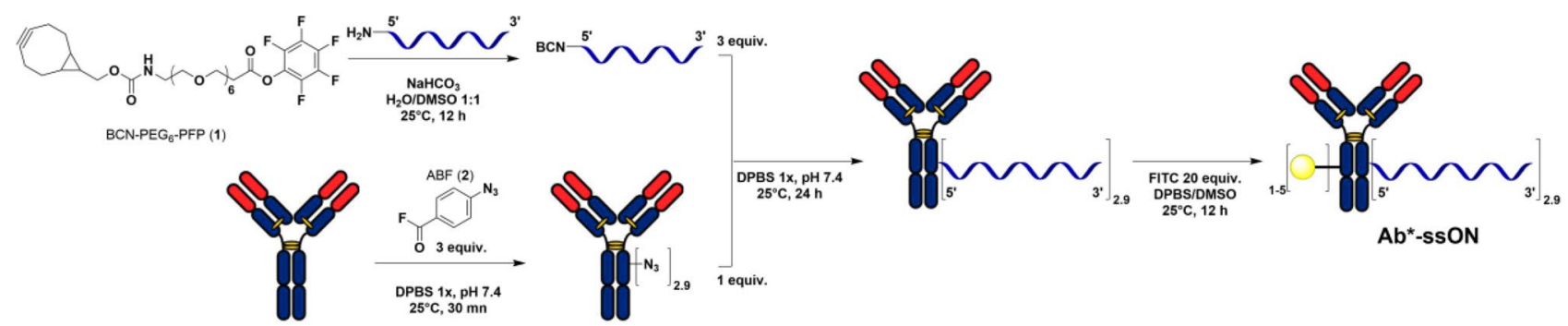

Figure 1. General scheme for the synthesis and labelling of $\mathrm{Ab}^{*}-\mathrm{ssON}$ conjugates.

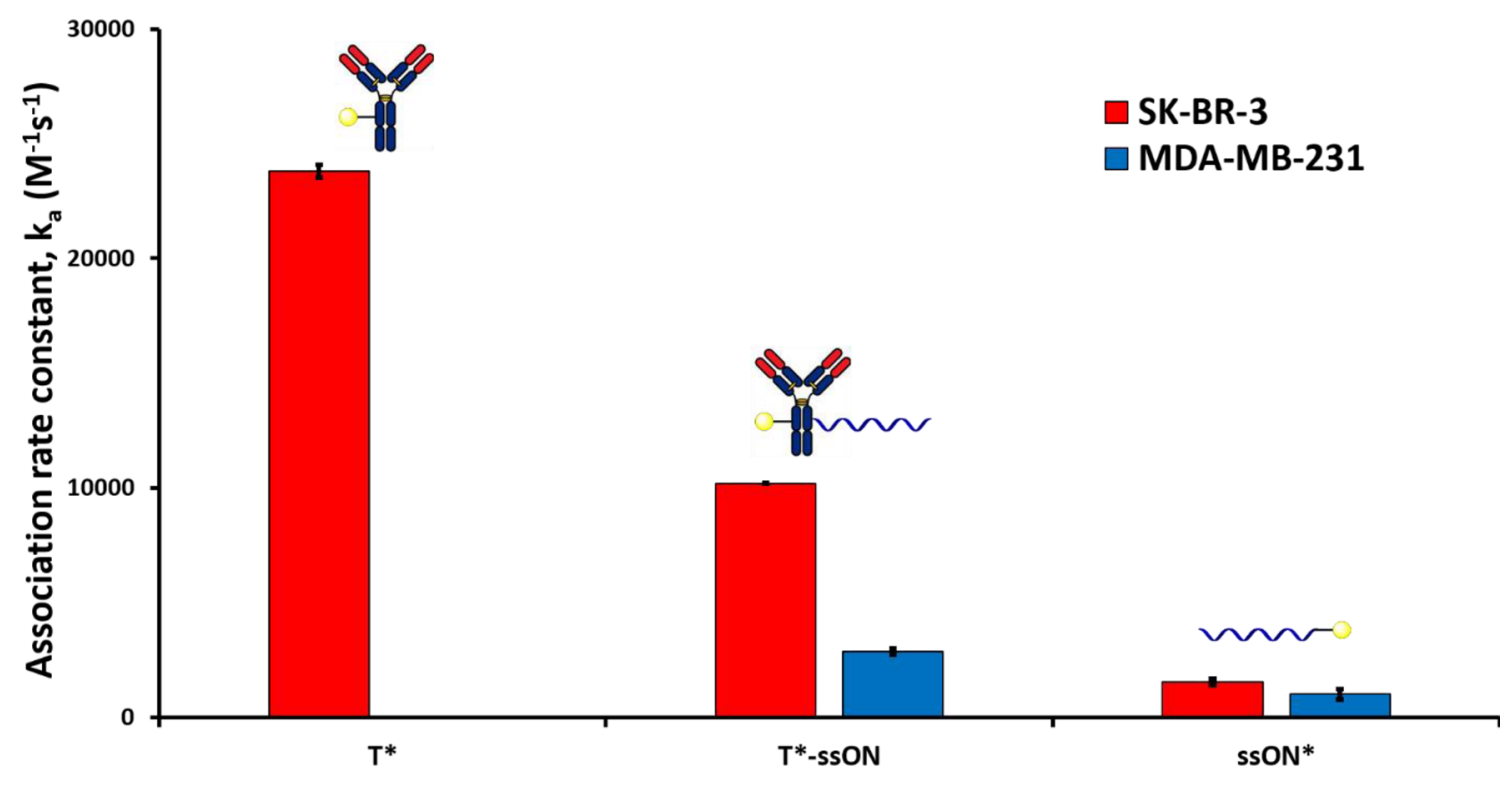

Figure 2. Association rate constants $\left(\mathrm{k}_{\mathrm{a}}\right)$ of unconjugated trastuzumab $\left(\mathrm{T}^{\star}\right)$, trastuzumab- single-stranded ON conjugate $\left(\mathrm{T}^{\star}\right.$-ssON) and free single stranded ON $\left(\mathrm{ssON}^{\star}\right)$ on SK-BR-3 (HER2 ${ }^{+}$cell line, red bars) and MDA-MB-231 (HER2- cell line, blue bars) measured using the time-resolved analysis of ligand binding assay (Fig. S3, S4, and S13). The symbol * indicates fluorescein labelling. Error bars indicate the standard error of the fitted parameter $\mathrm{k}_{\mathrm{a}}$.

\section{Results and discussion}

Using a previously reported plug and play conjugation strategy ${ }^{7}$, we prepared several fluorescein-labelled proteins and protein-ON conjugates (see Fig. 1, 5, S1, S2 and Table S1 for syntheses and characterization of the conjugates) with Degrees of Conjugation (DoC) in line with those of our previously-described DNA-linked ADCs ${ }^{2}$ (i.e. comprised between 2 and 3). We then evaluated the interaction profiles of these protein-ON conjugates with two cell lines, SK-BR-3 (HER2 ${ }^{+}$) and MDA-MB-231 (HER2 ${ }^{-}$), using time-resolved analysis of ligand binding assay $^{8,9}$. As an HER2 targeting antibody, we used trastuzumab and as negative controls, we used the anti-CD20 antibody rituximab and Human Serum Albumin (HSA).

In the following figures, we will report association rate constant values $\mathrm{k}_{\mathrm{a}}\left(\mathrm{M}^{-1} \mathrm{~s}^{-1}\right)$, describing the rate of formation of complexes, i.e. the number of fluorescein-labelled compounds bound to cell membranes per second. Thus, high $\mathrm{k}_{\mathrm{a}}$ value will account for fast binding to cell surface, while low value will account for slow to no interaction. The values of $\mathrm{k}_{\mathrm{a}}$ in biological systems are typically comprised between $1.10^{3}$ and $1.10^{7} \mathrm{M}^{-1} \mathrm{~s}^{-1}$. We chose to study this parameter to compare specific and non-specific interactions as it was previously shown to be largely insensitive to differences between binding patterns ${ }^{10}$.

In a first set of experiments, we compared the association rate constants of anti-HER2 antibody trastuzumab $\left(\mathrm{T}^{\star}\right)$, trastuzumab-37mer ssON conjugate $\left(\mathrm{T}^{*}\right.$-ssON), and single-stranded $37 \mathrm{mer} s \mathrm{ss}\left(\mathrm{ssON}^{*}\right)$, on both cell lines (Fig. 2). In order to do so, cells were seeded on a cell dish and incubated with fluorescein-labelled compounds (the symbol * indicates fluorescein labelling). The fluorescence intensity was then measured over time and normalized against the background fluorescence of the plastic support (see Fig. S3 to S16). The signal increase was used to extract the association rate constant $\mathrm{k}_{\mathrm{a}}$.

Unsurprisingly, trastuzumab displayed a high selectivity profile with an association rate constant $\mathrm{k}_{\mathrm{a}}$ of $23,800 \mathrm{M}^{-1} \mathrm{~s}^{-1}$ on the HER2 ${ }^{+}$cell line, while no signal variation was detected for the HER2 ${ }^{-}$cell line. $\mathrm{T}^{*}$-ssON showed a deteriorated selectivity profile with a reduced $\mathrm{k}_{\mathrm{a}}$ for HER2 ${ }^{+}$cells, but more importantly with the appearance of "non-specific" interactions with HER2- cells. Stochastic conjugation with lysine residues ${ }^{11,12}$ for $\mathrm{T}^{\star}$-ssON might account for the lower $\mathrm{k}_{\mathrm{a}}$ with the HER2 ${ }^{+}$cell line as compared to unconjugated $\mathrm{T}^{\star}$. Indeed, 


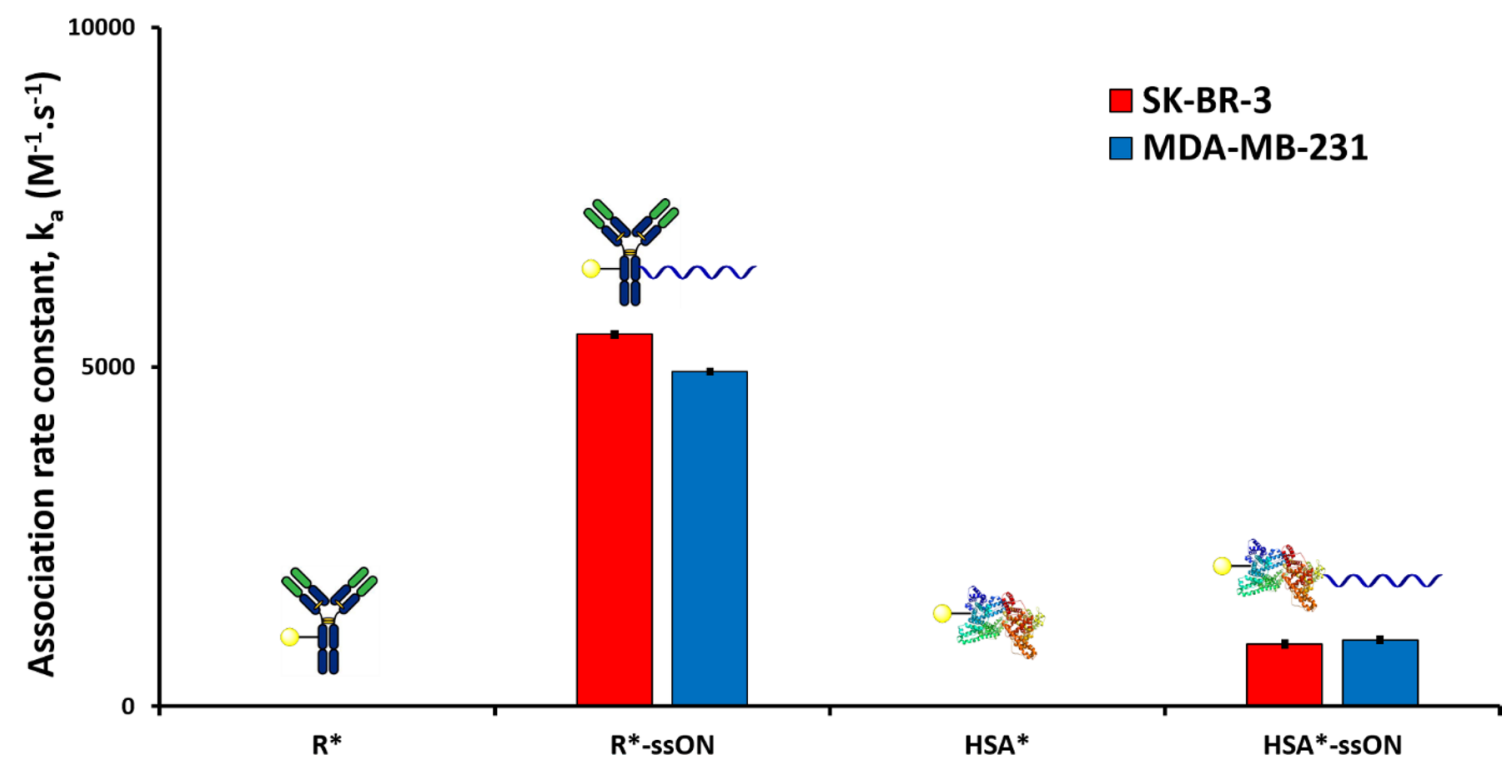

Figure 3. Association rate constants $\left(\mathrm{k}_{\mathrm{a}}\right)$ of unconjugated rituximab $\left(\mathrm{R}^{\star}\right)$, single stranded rituximab-ssON conjugate $\left(\mathrm{R}^{*}\right.$-ssON), unconjugated $\mathrm{HSA}\left(\mathrm{HSA}^{\star}\right)$, and single stranded HSA-ssON conjugate $\left(\mathrm{HSA}^{*}\right.$-ssON) on SK-BR-3 (HER2 ${ }^{+}$cell line, red bars) and MDA-MB-231 (HER2 ${ }^{-}$cell line, blue bars) measured using the timeresolved analysis of ligand binding assay (Fig. S7-10). The symbol * indicates fluorescein-labelling. Error bars indicate the standard error of the fitted parameter $\mathrm{k}_{\mathrm{a}}$.

random conjugation of payloads, including dyes ${ }^{11}$ and small-molecule drugs ${ }^{12,13}$, to an antibody was reported to deteriorate its antigen affinity in some cases.

It is noteworthy that ssON* showed an HER2-independant interaction with both cell lines, as evidenced by low but significant values of $\mathrm{k}_{\mathrm{a}}$ on both SK-BR-3 and MDA-MB-231 cell lines. The order of magnitude of these interactions falls in the same range as that of $\mathrm{T}^{\star}$-ssON on HER2- cells, advocating for the fact that the latter was the result of $\mathrm{ON}$-cell interactions.

To validate this observation, we conjugated the same single-stranded 37 mer ON to rituximab (R), an antibody targeting B-lymphocyte antigen CD20 (an antigen that is expressed by neither SK-BR-3 nor MDA-MB-231), and to HSA (Fig. 3).

As expected, both non-conjugated rituximab $\left(\mathrm{R}^{\star}\right)$ and $\mathrm{HSA}\left(\mathrm{HSA}^{\star}\right)$ showed no interaction with either cell line. On the other hand, the corresponding ON conjugated $\mathrm{R}^{\star}$-ssON and $\mathrm{HSA}^{*}$-ssON were shown to interact to an undeniable extent with both cell lines (Fig. 3), which is consistent with our previous observation that the conjugation of an $\mathrm{ON}$ to a protein induces an interaction with cells that is mediated by the ON moiety and not the protein. Interestingly, this effect was more pronounced with $\mathrm{R}^{\star}$-ssON than $\mathrm{HSA}^{\star}$-ssON, indicating that different proteins might be impacted differently by $\mathrm{ON}$ conjugation.

To gain further evidence, we performed a competition assay, where MDA-MB-231 cells, supposedly interacting with $\mathrm{T}^{\star}$-ssON via non-specific interactions, were pre-incubated with a 100 -fold excess of free $37 \mathrm{mer} s \mathrm{ON}$, relative to $\mathrm{T}^{\star}$-ssON (Fig. S17).

As expected, we found that the addition of free ssON to the medium almost completely prevented the further association of $\mathrm{T}^{*}$-ssON with MDA-MB-231, suggesting a shielding effect from the free ssON.

We then evaluated the influence of the ONs' length and hybridization on the association rate constant by comparing single and double stranded forms of non-coding and non-structured 20mers, 37 mers and 74 mers. In all cases, weak interactions with both cell lines were observed, with consistently higher values for single-stranded species (Fig. 4 and SI).

In the context of drug delivery applications of $\mathrm{AOCs}^{2,14-20}$, the $\mathrm{ON}$ component is often hybridized with its complementary strand in the form of double-stranded ONs (dsONs). As this could lead to weaker interactions with cell membranes, based on the results in Fig. 4, we set to prepare a dsON version of our trastuzumab conjugate $\left(\mathrm{T}^{*}\right.$-dsON) in order to evaluate the effect of such structural change. A first method to prepare this conjugate consists in the hybridization of a complementary ssON (cON) to the previously synthesized T-ssON. This is typically done by a brief incubation at $37^{\circ} \mathrm{C}$ of the two partners, in order to prevent degradation of the antibody (method 1, Fig. 5). This approach is mostly employed for non-covalent conjugation ${ }^{21}$ between two molecules that had been separately conjugated with complementary $s \mathrm{ONs}^{2,20,22,23}$. The validity of this approach is supported by the many examples of immunoassays (e.g. immuno-PCR ${ }^{24,25}$, proximity extension assay ${ }^{26,27}$, protein arrays $^{28}$ ), which rely upon hybridization steps that proceed under similar conditions. A second method consists in hybridizing the two strands under classical conditions (i.e. by incubation at $95^{\circ} \mathrm{C}$ ) prior to the bioconjugation step (method 2, Fig. 5). This method has been reported for the synthesis of antibody-siRNA conjugates from commercial chemically-modified duplexed siRNAs ${ }^{14,16}$. We produced $\mathrm{T}^{*}$-dsON conjugates with identical DoC values of 2.9 (determined by SDS-PAGE gel analysis; see Fig. S1) using both methods and compared their interaction rate constants to those of $\mathrm{T}^{\star}$-ssON on both cell lines (Fig. 6). 


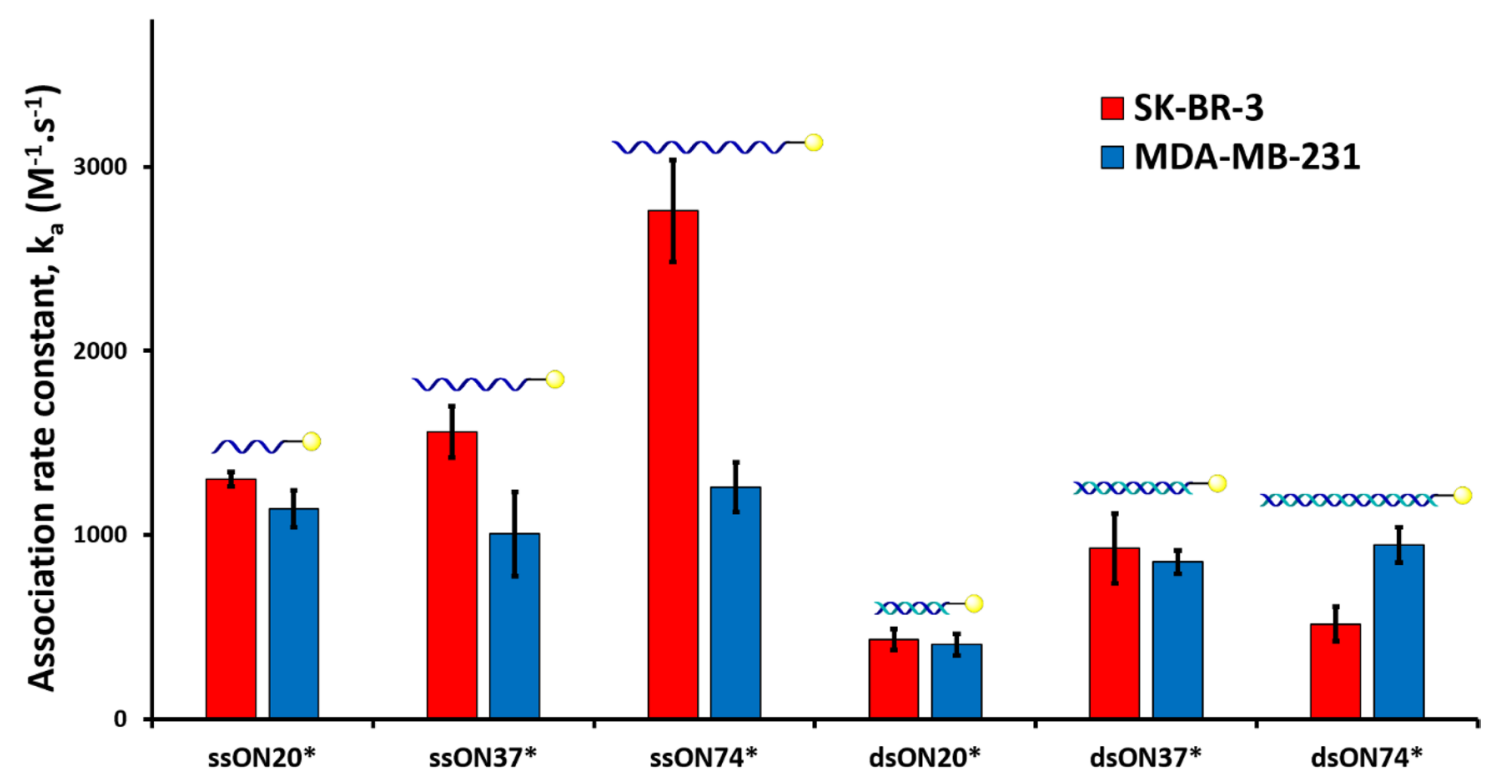

Figure 4. Association rate constants $\left(\mathrm{k}_{\mathrm{a}}\right)$ of free $20 \mathrm{mer}, 37 \mathrm{mer}$, and $74 \mathrm{mer}$, single and double-stranded ONs (respectively ssON20*, ssON37*, ssON74* and dsON20*, dsON37*, dsON74*) on SK-BR-3 (HER2 ${ }^{+}$cell line, red bars) and MDA-MB-231 (HER2 ${ }^{-}$cell line, blue bars) measured using the time-resolved analysis of ligand binding assay (Fig. S11-16). The symbol * indicates fluorescein-labelling. Error bars indicate the standard error of the fitted parameter $\mathrm{k}_{\mathrm{a}}$.

Method 1:
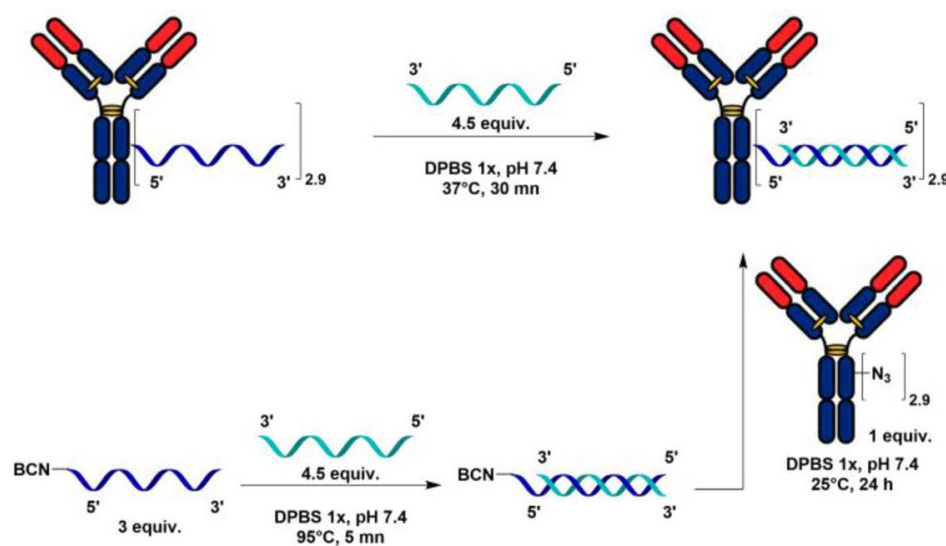

$95^{\circ} \mathrm{C}, 5 \mathrm{mn}$
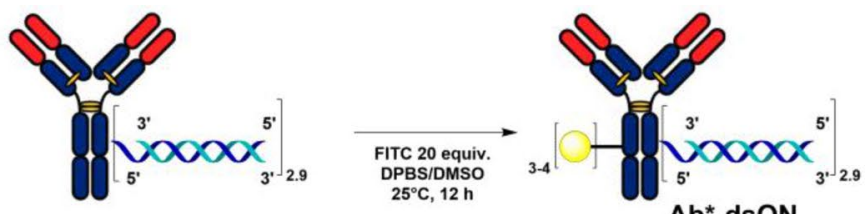

$A b^{*}$-dsON

Method 2:

Figure 5. General scheme for the synthesis and labelling of $\mathrm{Ab}^{\star}$-dsON conjugates.

For the $\mathrm{T}^{\star}$-dsON conjugates prepared following the first method, switching from single to double-stranded ONs gave comparable non-specific interactions, and also resulted in a slight decrease in $\mathrm{k}_{\mathrm{a}}$, notably on the HER2 ${ }^{+}$ SK-BR-3 cell line. Interestingly, the conjugate prepared following the second method had similar $\mathrm{k}_{\mathrm{a}}$ with SK-BR-3 cells but did not display non-specific interactions with MDA-MB-231 cells.

In the polymerase chain reaction (PCR), full hybridization of ONs is highly dependent on temperature, and the initial denaturation step is typically performed at $94{ }^{\circ} \mathrm{C}^{29}$. Incubation at $90-95{ }^{\circ} \mathrm{C}$ is thus commonly used for the hybridization of complementary ssONs into dsONs, as in the case of method 2 (Fig. 5). Performing the hybridization at lower temperature is useful when working with protein-ssON conjugates, since they are prone to undergo thermal denaturation, but it might not be sufficient to reach full hybridization (method 1, Fig. 5). This could account for the interaction profile of the $\mathrm{T}^{*}$-dsON conjugate prepared by method 1 which is halfway between that of the fully hybridized $\mathrm{T}^{*}$-dsON, prepared by method 2 , and that of $\mathrm{T}^{*}$-ssON.

The association of naked ONs with cells surface has now been studied for more than 50 years, with many cellsurface proteins proposed as receptors ${ }^{4}$. It has been documented that various types of ONs might bind to different receptors. As an example, toll-like receptors (TLRs), involved in the innate immune response, possess the ability to bind DNA molecules containing CpG motifs, dsRNAs as well as ssRNAs ${ }^{30}$. Cell-surface receptors of the scavenger receptors family, such as stabilin, have been reported to bind and internalize phosphorothioate-modified oligodeoxynucleotides $^{31}$, despite some conflicting results having been published ${ }^{32}$. Furthermore, proteins of the 


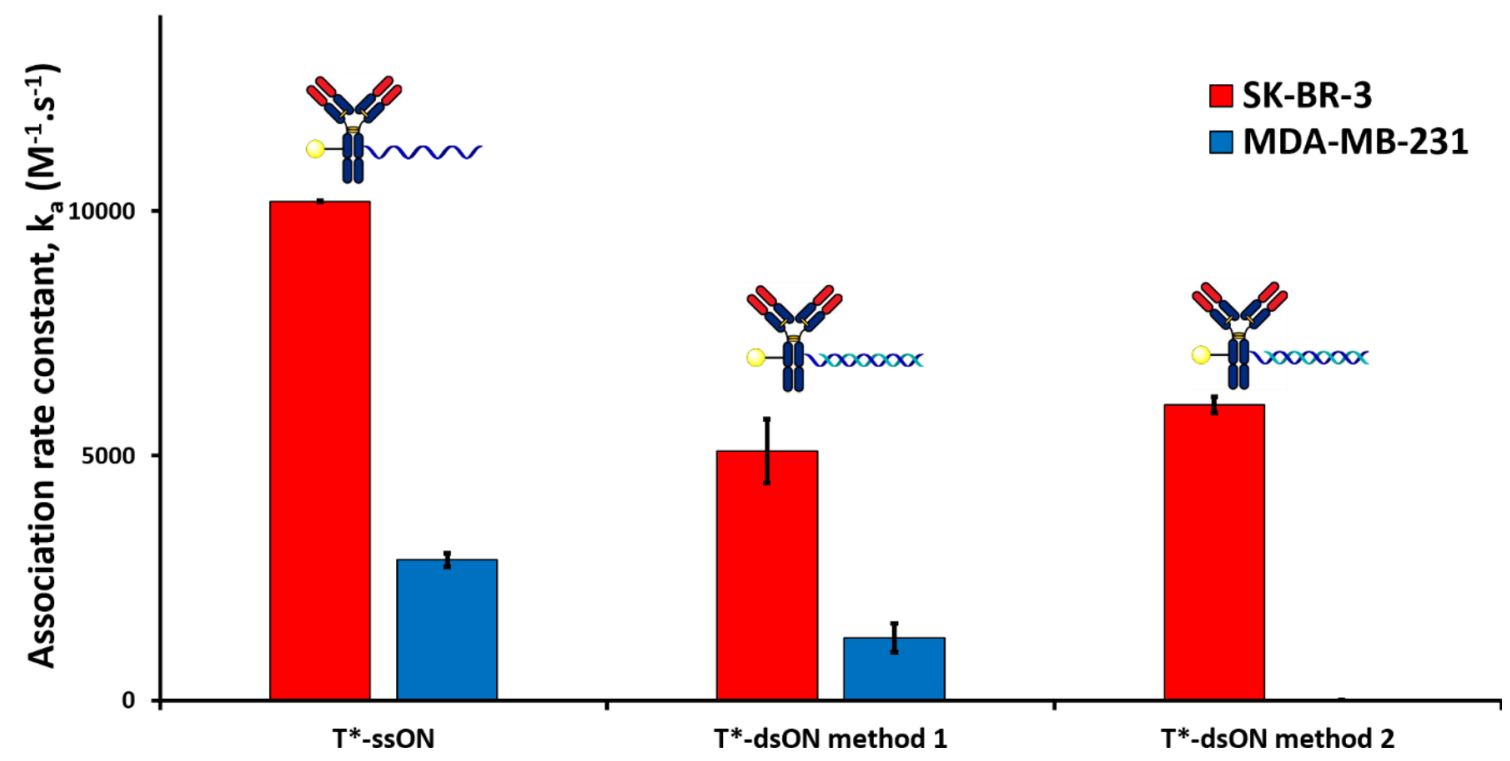

Figure 6. Association rate constants $\left(\mathrm{k}_{\mathrm{a}}\right)$ of single and double stranded trastuzumab-ssON conjugate $\left(\mathrm{T}^{*}\right.$-ssON and $\mathrm{T}^{\star}$-dsON, respectively), and free single and double stranded $\mathrm{ONs}\left(\mathrm{ssON}^{\star}\right.$ and $\mathrm{dsON} \mathrm{N}^{\star}$, respectively) on SK-BR-3 (HER2 ${ }^{+}$cell line, red bars) and MDA-MB-231 (HER2 ${ }^{-}$cell line, blue bars) measured using the timeresolved analysis of ligand binding assay (Fig. S4-6). The symbol * indicates fluorescein-labelling. Regarding the $\mathrm{T}^{*}$-dsON conjugates modes of preparation, method 1 corresponds to the hybridization of the complementary ON strand with the T-ssON conjugate, while method 2 corresponds to the conjugation of a hybridized dsON to trastuzumab (see Fig. 5). Error bars indicate the standard error of the fitted parameter $k_{\mathrm{a}}$.

systemic RNA interference defective protein 1 (SID1) transmembrane family, such as SIDT-1 and SIDT-2, have been shown to facilitate the uptake of ssRNA and dsRNA but not of ssDNA and dsDNA ${ }^{33-35}$.

Our results show that, when conjugated to an antibody, ONs are not simple linkers nor spectator payloads. Based on the present work and this body of literature, our group is currently investigating further the mechanism by which these interactions between AOCs and cell membranes operate at the molecular level and can be controlled.

\section{Conclusion}

As AOCs are developing into powerful tools in various applications ${ }^{1}$, investigations to get a better understanding of their interactions with cell surfaces appear to be stimulating a renewed interest ${ }^{30}$. Our previous ${ }^{2}$ and present results show that ONs are a particular payload that may display weak but consistent interactions with cell surfaces, which can impact the binding properties of antibodies upon conjugation. We demonstrate that both the nature of the $\mathrm{ON}$, single strand $v s$ double strand, as well as the method used to prepare the dsON AOC have a clear impact on the non-specific interaction of the resulting conjugates. This phenomenon is likely to disturb the in vitro and in vivo behavior of AOCs and influence their fate beyond what can be extrapolated from the knowledge of classical protein conjugates. As such, it appears that both ON structure and preparation method should be taken into consideration when developing antibody-oligonucleotide conjugates for imaging, detection or therapeutic application.

\section{Materials and methods}

All reagents were obtained from commercial sources and used without prior purifications. Amino-modified (5AmMC12) oligonucleotides were purchased from IDT. Protein-oligonucleotide conjugates were purified by gel filtration using ÄKTA Pure System (isocratic elution with DPBS 1x, pH 7.5, $0.5 \mathrm{~mL} / \mathrm{mn}$, column: Superdex 200 Increase 10/300 GL). The oligonucleotide species were purified using a Shimadzu HPLC system (pumps: LC 20-AD, detector: SPD 20-A, autosampler: SIL 20-A) using a XTerra MS C18 $5 \mu \mathrm{M} 4.6 \times 150 \mathrm{~mm}$ column (Waters), with a flow rate of $1 \mathrm{~mL} / \mathrm{mn}$ (Mobile phase: A triethylammonium acetate $50 \mathrm{mM}$ in water, $\mathbf{B}$ triethylammonium acetate $50 \mathrm{mM}$ in acetonitrile).

Conjugates synthesis. Oligonucleotide functionalization. BCN-PEG 6 -PFP (1) was synthesized as previously described $^{7}$. In a $2 \mathrm{~mL}$ Eppendorf tube, $5^{\prime}$-amino-modified oligonucleotide ( 1 equiv., $50 \mu \mathrm{L}, 1 \mathrm{mM}$ in water) was combined with 1 (20 equiv., $50 \mu \mathrm{L}, 20 \mathrm{mM}$ in DMSO) and $\mathrm{NaHCO}_{3}$ (100 equiv., $5 \mu \mathrm{L}, 1 \mathrm{M}$ in water). The mixture was incubated at $25^{\circ} \mathrm{C}$ overnight. The mixture was then diluted with water to a final volume of $300 \mu \mathrm{L}$ and added with acetone $(900 \mu \mathrm{L})$ and $\mathrm{LiClO}_{4}(20 \mu \mathrm{L}, 3 \mathrm{M}$ in water) in order to precipitate the oligonucleotide species. The sample was then centrifuged $(15,000 \mathrm{G}, 8 \mathrm{mn})$ and the supernatant was discarded. The precipitate was dissolved with water $(300 \mu \mathrm{L})$ to repeat the precipitation and centrifugation procedure a second time. 
Oligonucleotide purification. The previously obtained precipitate was then dissolved with water $(100 \mu \mathrm{L})$ and purified by HPLC (detection at $260 \mathrm{~nm}$, mobile phase gradient A/B 9:1 to 6:4 in $30 \mathrm{mn}$ ). After lyophilization, the ON conjugate was dissolved in DPBS (1x, pH 7.4) and analyzed by absorption spectrophotometry (measured at $260 \mathrm{~nm}$ using a Nanodrop) to calculate the solution's concentration using Beer-Lambert's law.

Protein azido-functionalization. 4-azidobenzoyl fluoride (ABF, 2) was synthetized as previously described ${ }^{7} .2$ (3 equiv., $10 \mathrm{mM}$ in DMSO) was added to a solution of protein (1 equiv., $5 \mathrm{mg} / \mathrm{mL}, 100 \mu \mathrm{L}$ in DPBS $1 \mathrm{x}, \mathrm{pH} 7.4$ ) and the reaction mixture was incubated at $25^{\circ} \mathrm{C}$ for $30 \mathrm{~min}$. The excess of reagents was then removed by gel filtration chromatography using Bio-spin P-30 Columns (Bio-Rad, Hercules, U.S.A.) pre-equilibrated with DPBS $(1 \mathrm{x}, \mathrm{pH} 7.4)$ to give a solution of protein-azide conjugates, which was used in the following step.

Protein-oligonucleotide conjugates synthesis. The previously obtained 5'-BCN-modified oligonucleotide (3 equiv., $0.5-1 \mathrm{mM}$ in DPBS $1 \mathrm{x}$ ) and $10 \mu \mathrm{L}$ of DPBS $10 \times$ were added to a solution of the protein-azide conjugate ( 1 equiv., $5.0 \mathrm{mg} / \mathrm{mL}$, in $100 \mu \mathrm{L}$ DPBS $1 \mathrm{x}, \mathrm{pH} 7.4$ ). The mixture was purged with argon and incubated for $24 \mathrm{~h}$ at $25^{\circ} \mathrm{C}$. The conjugates were purified by gel filtration chromatography using AKTA Pure System (isocratic elution with DPBS (1x, pH 7.4), $0.5 \mathrm{~mL} / \mathrm{min}$ ) to yield the protein-oligonucleotide conjugates.

Fluorescein labelling. $\quad 5$ '-fluorescein labelled (56-FAM) oligonucleotides were purchased from IDT.

Proteins were concentrated to $1-5 \mathrm{mg} / \mathrm{mL}$ on micro-concentrators (Vivaspin, 50 and $10 \mathrm{kD}$ cutoff, for antibodies and HSA, respectively, Sartorius, Gottingen, Germany), and added with 20 equiv. of FITC (10 $\mathrm{mM}$ in DMSO). The mixture was then incubated at $25^{\circ} \mathrm{C}$ overnight. The excess of FITC was then removed by gel filtration chromatography using Bio-spin P-30 Columns (Bio-Rad, Hercules, U.S.A.) pre-equilibrated with DPBS 1x ( $\mathrm{pH} 7.5)$ to give a solution of FITC-labelled proteins.

Double stranded oligonucleotides and antibody-oligonucleotide conjugates synthesis. Free oligonucleotides were hybridized by stirring a solution of the complementary strands at an equimolar ratio $(100 \mu \mathrm{M})$ in DPBS $1 \times$ at $95^{\circ} \mathrm{C}$ for $5 \mathrm{mn}$, and then allowing the solution to come back to room temperature. The hybridized species were then purified from the non-hybridized ones using AKTA Pure System (isocratic elution with DPBS (1x, pH 7.4), $0.5 \mathrm{~mL} / \mathrm{min})$.

The double stranded AOCs were prepared by two methods (Fig. 5):

Method 1. T-ssON conjugate was mixed with an excess (4.5 equiv.) of complementary strand in DPBS 1x ( $\mathrm{pH}$ 7.4), incubated at $37^{\circ} \mathrm{C}$ for $30 \mathrm{~min}$, and purified by gel filtration chromatography using AKTA Pure System (isocratic elution with DPBS ( $1 \mathrm{x}, \mathrm{pH} 7.4), 0.5 \mathrm{~mL} / \mathrm{min}$ ) to yield T-dsON.

Method 2. 5'-BCN-modified oligonucleotide (3 equiv., 2.06 nmole, $400 \mu \mathrm{M}$ in DPBS 1x), and its complementary strand (4.5 equiv., 3.09 nmole, $1 \mathrm{mM}$ in DPBS $1 \mathrm{x}$ ) were mixed and stirred at $95^{\circ} \mathrm{C}$ for $5 \mathrm{~min}$, and then allowed to slowly return to room temperature. The mixture was then added with $3 \mu \mathrm{L}$ of DPBS 10x, and then with the above-described azido-modified trastuzumab ( 1 equiv., $100 \mu \mathrm{g}, 4.3 \mathrm{mg} / \mathrm{mL}$ ). After incubation at $25^{\circ} \mathrm{C}$ for $24 \mathrm{~h}$, the formed T-dsON37 conjugate was purified using AKTA Pure System (isocratic elution with DPBS (1x, pH 7.4), $0.5 \mathrm{~mL} / \mathrm{min})$.

Conjugates' characterization. Protein-oligonucleotide conjugates concentration determination. The concentration of a protein in a given solution can usually be determined by measuring its absorption at $280 \mathrm{~nm}$, and using Beer-Lambert's law. ON's absorbance at $280 \mathrm{~nm}$ thus makes it impossible to determine the concentration of protein-oligonucleotide conjugates through absorption spectrophotometry measurement.

Protein-oligonucleotide conjugates' concentration was then determined using Pierce BCA protein assay kit (ThermoFisher ref 23225), following the manufacturer's protocol. This method allows quantification of the protein moiety's concentration, regardless of the presence of conjugated ONs. Concentrations were used to calculate the yields of conjugation (see Table S1).

Protein-oligonucleotide conjugates DoC distribution determination by SDS PAGE. SDS-PAGE was performed on 4-20\% Mini-PROTEAN TGX Gel (Bio-Rad ref 4561094) following the manufacturer's procedure. Proteins, or protein-oligonucleotide conjugates $(24 \mu \mathrm{L}, 0.2 \mathrm{mg} / \mathrm{mL}$ in DPBS $1 \mathrm{x})$ were added with $8 \mu \mathrm{L}$ of non-reducing Laemmli SDS sample buffer (Alfa Aesar), and heated at $95^{\circ} \mathrm{C}$ for $5 \mathrm{mn}$. $10 \mu \mathrm{L}$ of the resulting solutions were deposited, and the gel was run at constant voltage $(200 \mathrm{~V})$ for $35 \mathrm{mn}$ using TRIS $0.25 \mathrm{M}$-Glycine $1.92 \mathrm{M}-\mathrm{SDS}$ $1 \%$ as a running buffer. Coomassie Blue staining was performed using InstantBlue solution, prior to visualization on GeneGenius bio-imaging system (Syngene).

The lines' intensities were determined using the Image Studio Lite 5.2 software (LI-COR Biosciences), and the DoC of each conjugate was calculated using the following formula (Eq. 1):

$$
D o C=\frac{\sum_{k} \mathrm{k} \times \mathrm{I}(\mathrm{DoCk})}{\sum_{k} \mathrm{I}(\mathrm{DoCk})}
$$

where $\mathrm{I}\left(\mathrm{DoC}_{\mathrm{k}}\right)$ is the line's intensity of the conjugate with $\mathrm{k}$ conjugated oligonucleotides per antibody. 
Additionally, we analyzed the deglycosylated azido-modified trastuzumab intermediate by native mass spectrometry (see figure S2). As observed in a previous work ${ }^{7}$, the mean DoC values obtained by integration of SDS-PAGE gel bands of the Ab-ssON conjugate (2.9) and native MS of the azido-modified intermediate (2.8) were closely correlated.

Proteins and protein-oligonucleotide conjugate degree of labelling (DoL) determination. After FITC-labelling, the fluorescein concentration of each protein and protein-ON conjugate was measured by absorption spectrophotometry using NanoDrop's "proteins and labels" mode.

The DoL of each compound was calculated using Eq. (2) (see Table S1).

$$
\text { DoL }=\frac{\text { fluorescein concentration }(M)}{\text { Protein concentration }(M)}
$$

For fluorescein-labelled proteins, the protein concentration was determined by absorption at $280 \mathrm{~nm}$, while for fluorescein-labelled protein-ON conjugates, it was determined by BCA assay (see above).

Binding assays. Cell culture. Human breast adenocarcinoma cells SK-BR-3 (ATCC HTB-30) and MDAMB-231 (ATCC HTB-26)) were grown in Dulbecco's Modified Eagle's Medium (DMEM) containing $4.5 \mathrm{~g} / \mathrm{L}$ glucose (Sigma, St Louis, MO, USA). The medium was supplemented with $10 \%$ fetal bovine serum (Perbio, Brebieres, France), $2 \mathrm{mM}$ L-Glutamine, $100 \mathrm{U} / \mathrm{mL}$ Penicillin and $100 \mu \mathrm{g} / \mathrm{mL}$ Streptomycin (Sigma). Cells were maintained in a $5 \% \mathrm{CO} 2$ humidified atmosphere at $37^{\circ} \mathrm{C}$.

SK-BR-3 cells overexpress HER2 protein, and MDA-MB-231 cells are used as negative controls.

The day before the experiment on Ligand Tracer Green (Ridgeview Instruments), cells were seeded as 600 $\mu \mathrm{L}$ droplets with $8 \times 105$ cells $/ \mathrm{mL}$ near the edge in $87 \mathrm{~mm}$ cell culture treated dishes (Greiner, Frickenhausen, Germany) and incubated at $37^{\circ} \mathrm{C}$ overnight. Two droplets were prepared with SK-BR-3, one with MDA-MB-231, and one was left as a background reference (plastic).

Prior to kinetic measurements, the medium was carefully removed and $3 \mathrm{~mL}$ of fresh complete medium was added to the dish.

Time-resolved analysis of ligand binding assays. We measured the interactions of fluorescein-labelled proteins and oligonucleotides with living cells in real-time using LigandTracer Green (Ridgeview intruments).

The Petri dish on which cells were grown (see above) was placed on the inclined rotating support of the instrument, with the Blue/Green detector placed on its upper part.

First, a baseline signal was collected for $30 \mathrm{~min}$. The fluorescein-labelled compound was then added in two steps at increasing concentrations $(10$ and $30 \mathrm{nM})$. Inclination of the Petri dish allows for the addition of the fluorescein-labelled compounds outside of the detection area. For each rotation of the Petri dish, the signal from the three areas containing cells (two spots for SK-BR-3, one for MDA-MB-231) and a background reference area (plastic) is recorded. Measurements last $30 \mathrm{~s}$ each, with $5 \mathrm{~s}$ in between each of them to allow the medium to sit in the lower part of the Petri dish. This results in three background-subtracted real-time binding curves, which represent the binding of the fluorescein-labelled compound to each cell-containing area.

For each concentration the incubation was performed until a sufficient curvature was obtained for the subsequent extraction of kinetic parameters. Dissociation of the ligand was recorded after replacing the incubation solution with $3 \mathrm{ml}$ of fresh medium.

Signals from cell and reference areas are recorded during every rotation, resulting in a background-subtracted binding curve. Binding traces were analyzed with the evaluation software TraceDrawer 1.8.1 (Ridgeview Instruments) in order to determine $\mathrm{k}_{\mathrm{a}}$ according to the Langmuir, or "one-to-one", binding model.

Competition assay. After collection of the baseline signal, 100 equiv. of unlabelled ssON37 (relative to the total added amount of $\mathrm{T}^{\star}$-ssON) were added to the medium. After $30 \mathrm{mn}$, the time-resolved analysis of $\mathrm{T}^{\star}$-ssON binding was performed as previously described (Fig. S17).

Received: 16 July 2020; Accepted: 29 January 2021

Published online: 15 March 2021

\section{References}

1. Dovgan, I., Koniev, O., Kolodych, S. \& Wagner, A. Antibody-oligonucleotide conjugates as therapeutic, imaging, and detection agents. Bioconjug. Chem. 30(10), 2483-2501. https://doi.org/10.1021/acs.bioconjchem.9b00306 (2019).

2. Dovgan, I. et al. On the use of DNA as a linker in antibody-drug conjugates: synthesis, stability and in vitro potency. Sci. Rep. 10(1), 1-9. https://doi.org/10.1038/s41598-020-64518-y (2020).

3. Walker, I., Irwin, W. J. \& Akhtar, S. Improved cellular delivery of antisense oligonucleotides using transferrin receptor antibodyoligonucleotide conjugates. Pharm. Res. 12(10), 1548-1553. https://doi.org/10.1023/A:1016260110049 (1995).

4. Bennett, R. M. As nature intended? The uptake of DNA and oligonucleotides by eukaryotic cells. Antisense Res. Dev. 3(3), $235-241$. https://doi.org/10.1089/ard.1993.3.235 (1993).

5. Lu, T. et al. The non-specific binding of fluorescent-labeled MiRNAs on cell surface by hydrophobic interaction. PLoS ONE 11(3), e0149751. https://doi.org/10.1371/journal.pone.0149751 (2016).

6. Bondza, S., Stenberg, J., Nestor, M., Andersson, K. \& Björkelund, H. Conjugation effects on antibody-drug conjugates: evaluation of interaction kinetics in real time on living cells. Mol. Pharm. 11(11), 4154-4163. https://doi.org/10.1021/mp500379d (2014). 
7. Dovgan, I. et al. Acyl fluorides: fast, efficient, and versatile lysine-based protein conjugation via plug-and-play strategy. Bioconjug. Chem. 28(5), 1452-1457. https://doi.org/10.1021/acs.bioconjchem.7b00141 (2017).

8. Björke, H. \& Andersson, K. Measuring the affinity of a radioligand with its receptor using a rotating cell dish with in situ reference area. Appl. Radiat. Isot. Data Instrum. Methods Use Agric. Ind. Med. 64(1), 32-37. https://doi.org/10.1016/j.apradiso.2005.06.007 (2006).

9. Björke, H. \& Andersson, K. Automated, high-resolution cellular retention and uptake studies in vitro. Appl. Radiat. Isot. Data Instrum. Methods Use Agric. Ind. Med. 64(8), 901-905. https://doi.org/10.1016/j.apradiso.2006.03.002 (2006).

10. Bondza, S. et al. Real-time characterization of antibody binding to receptors on living immune cells. Front. Immunol. 8, 455. https ://doi.org/10.3389/fimmu.2017.00455 (2017).

11. Szabó, Á. et al. The effect of fluorophore conjugation on antibody affinity and the photophysical properties of dyes. Biophys. J. 114(3), 688-700. https://doi.org/10.1016/j.bpj.2017.12.011 (2018).

12. Buecheler, J. W., Winzer, M., Weber, C. \& Gieseler, H. Alteration of physicochemical properties for antibody-drug conjugates and their impact on stability. J. Pharm. Sci. 109(1), 161-168. https://doi.org/10.1016/j.xphs.2019.08.006 (2020).

13. Acchione, M., Kwon, H., Jochheim, C. M. \& Atkins, W. M. Impact of linker and conjugation chemistry on antigen binding, Fc receptor binding and thermal stability of model antibody-drug conjugates. MAbs 4(3), 362-372. https://doi.org/10.4161/mabs.19449 (2012).

14. Leng, Q., Woodle, M. C. \& Mixson, A. J. Targeted Delivery of siRNA Therapeutics to Malignant Tumors https://www.hindawi.com/ journals/jdd/2017/6971297/ (accessed Mar 26, 2020). .https://doi.org/10.1155/2017/6971297.

15. Liu, T. et al. Selective delivery of doxorubicin to EGFR+ cancer cells by cetuximab-DNA conjugates. ChemBioChem 20(8), 10141018. https://doi.org/10.1002/cbic.201800685 (2019).

16. Cuellar, T. L. et al. Systematic evaluation of antibody-mediated SiRNA delivery using an industrial platform of THIOMAB-SiRNA conjugates. Nucleic Acids Res. 43(2), 1189-1203. https://doi.org/10.1093/nar/gku1362 (2015).

17. Liu, G. et al. Pretargeting CWR22 prostate tumor in mice with MORF-B723 antibody and radiolabeled CMORF. Eur. J. Nucl. Med. Mol. Imaging 35(2), 272-280. https://doi.org/10.1007/s00259-007-0606-z (2008).

18. Liu, G. et al. A novel pretargeting method for measuring antibody internalization in tumor cells. Cancer Biother. Radiopharm. 22(1), 33-39. https://doi.org/10.1089/cbr.2006.339 (2007)

19. Verhoeven, M., Seimbille, Y. \& Dalm, S. U. Therapeutic applications of pretargeting. Pharmaceutics https://doi.org/10.3390/pharm aceutics11090434 (2019).

20. Hsu, N.-S. et al. Development of a versatile and modular linker for antibody-drug conjugates based on oligonucleotide strand pairing. Bioconjug. Chem. 31(7), 1804-1811. https://doi.org/10.1021/acs.bioconjchem.0c00281 (2020).

21. Schreiber, C. L. \& Smith, B. D. Molecular conjugation using non-covalent click chemistry. Nat. Rev. Chem. 3(6), 393-400. https:// doi.org/10.1038/s41570-019-0095-1 (2019).

22. Rosier, B. J. H. M. et al. Incorporation of native antibodies and fc-fusion proteins on DNA nanostructures via a modular conjugation strategy. Chem. Commun. 53(53), 7393-7396. https://doi.org/10.1039/C7CC04178K (2017)

23. Kuijpers, W. H., Bos, E. S., Kaspersen, F. M., Veeneman, G. H. \& van Boeckel, C. A. Specific recognition of antibody-oligonucleotide conjugates by radiolabeled antisense nucleotides: a novel approach for two-step radioimmunotherapy of cancer. Bioconjug. Chem. 4(1), 94-102. https://doi.org/10.1021/bc00019a013 (1993).

24. Kazane, S. A. et al. Site-Specific DNA-antibody conjugates for specific and sensitive immuno-PCR. Proc. Natl. Acad. Sci. 109(10), 3731-3736. https://doi.org/10.1073/pnas.1120682109 (2012).

25. Li, G. et al. An activity-dependent proximity ligation platform for spatially resolved quantification of active enzymes in single cells. Nat. Commun. 8(1), 1775. https://doi.org/10.1038/s41467-017-01854-0 (2017).

26. Leino, M. et al. Optimization of proximity-dependent initiation of hybridization chain reaction for improved performance. Mol. Syst. Des. Eng. 4(5), 1058-1065. https://doi.org/10.1039/C9ME00079H (2019).

27. Koos, B. et al. Proximity-dependent initiation of hybridization chain reaction. Nat. Commun. 6(1), 7294. https://doi.org/10.1038/ ncomms8294 (2015).

28. Niemeyer, C. M., Boldt, L., Ceyhan, B. \& Blohm, D. DNA-directed immobilization: efficient, reversible, and site-selective surface binding of proteins by means of covalent DNA-streptavidin conjugates. Anal. Biochem. 268(1), 54-63. https://doi.org/10.1006/ abio.1998.3017 (1999).

29. Rychlik, W., Spencer, W. J. \& Rhoads, R. E. Optimization of the annealing temperature for DNA amplification in vitro. Nucleic Acids Res. 18(21), 6409-6412. https://doi.org/10.1093/nar/18.21.6409 (1990).

30. Juliano, R. L., Ming, X., Carver, K. \& Laing, B. Cellular uptake and intracellular trafficking of oligonucleotides: implications for oligonucleotide pharmacology. Nucleic Acid Ther. 24(2), 101-113. https://doi.org/10.1089/nat.2013.0463 (2014).

31. Miller, C. M. et al. Stabilin-1 and Stabilin-2 are specific receptors for the cellular internalization of phosphorothioate-modified antisense oligonucleotides (ASOs) in the liver. Nucleic Acids Res. 44(6), 2782-2794. https://doi.org/10.1093/nar/gkw112 (2016).

32. Butler, M. et al. Phosphorothioateoligodeoxynucleotides distribute similarly in class a scavenger receptor knockout and wild-type mice. J. Pharmacol. Exp. Ther. 292(2), 489-496 (2000).

33. Duxbury, M. S., Ashley, S. W. \& Whang, E. E. RNA interference: a mammalian SID-1 homologue enhances SiRNA uptake and gene silencing efficacy in human cells. Biochem. Biophys. Res. Commun. 331(2), 459-463. https://doi.org/10.1016/j.bbrc.2005.03.199 (2005).

34. Wolfrum, C. et al. Mechanisms and optimization of in vivo delivery of lipophilic SiRNAs. Nat. Biotechnol. 25(10), 1149-1157. https://doi.org/10.1038/nbt1339 (2007).

35. Takahashi, M. et al. SIDT2 mediates gymnosis, the uptake of naked single-stranded oligonucleotides into living cells. RNA Biol. 14(11), 1534-1543. https://doi.org/10.1080/15476286.2017.1302641 (2017).

\section{Acknowledgements}

International Center for Frontier Research in Chemistry (icFRC), Region Alsace and the French Proteomic Infrastructure (ProFI; ANR-10-INBS-08-03) are acknowledged for their financial support.

\section{Author contributions}

V.L. synthesized the conjugates, I.K. and M.N. performed the binding assays, S.E. performed the MS experiments, V.L. and A.W. wrote the manuscript, S.K., S.C., and G.C. contributed to the interpretation of results and revised the manuscript critically, S.C., and A.W. supervised the project. All authors reviewed the manuscript.

\section{Competing interests}

The authors declare no competing interests.

\section{Additional information}

Supplementary Information The online version contains supplementary material available at https://doi. 
org/10.1038/s41598-021-85352-w.

Correspondence and requests for materials should be addressed to A.W.

Reprints and permissions information is available at www.nature.com/reprints.

Publisher's note Springer Nature remains neutral with regard to jurisdictional claims in published maps and institutional affiliations.

(c) (i) Open Access This article is licensed under a Creative Commons Attribution 4.0 International

License, which permits use, sharing, adaptation, distribution and reproduction in any medium or format, as long as you give appropriate credit to the original author(s) and the source, provide a link to the Creative Commons licence, and indicate if changes were made. The images or other third party material in this article are included in the article's Creative Commons licence, unless indicated otherwise in a credit line to the material. If material is not included in the article's Creative Commons licence and your intended use is not permitted by statutory regulation or exceeds the permitted use, you will need to obtain permission directly from the copyright holder. To view a copy of this licence, visit http://creativecommons.org/licenses/by/4.0/.

(C) The Author(s) 2021 